\title{
1990 E-MRS Spring Meeting Set for Strasbourg
}

The 1990 Spring Meeting of the European Materials Research Society will be held May 29 through June 1 at the Council of Europe facilities, Strasbourg, France. This meeting especially seeks to focus "on creating the synergy between interdisciplinary, innovative technologies, on diffusing and exchanging information and promoting technology transfer towards industry."

Papers are being solicited for the five symposia described below. Abstracts are due March 1, 1990 and can be submitted to the symposium organizers, also identified below.

A Summer School on Metal Matrix Composites is being planned May 25-29, prior to the meeting. K. Kainer, Materials Department, Claustal University, is the organizer of the summer school. More information will be available in upcoming E-MRS conference announcements.

For more information or to register for the 1990 E-MRS Spring Meeting contact:

Conference Secretariat

Paul Siffert

Centre de Recherches Nucléaires

E-MRS 1990 Spring Conference

B.P. 20

F-67037 Strasbourg Cedex

France

Telephone 88286543

Fax 88280990

\section{Symposium A-High $T_{c}$}

\section{Superconductor Materials}

This symposium will highlight recent developments in the materials science and physics of high $T_{c}$ superconductors as well as applications. Topics will range from fundamental understanding of the physical properties of high $T_{c}$ superconducting materials to the assessment of high $T_{c}$ thin films and bulk material for device and other applications. Guideline topics for papers include: emerging materials; structure-properties relationship; bulk material, microstructure and applications; single crystals; thin films, preparation, patterning and devices; physical properties; and characterization of high $\mathrm{T}_{\mathrm{c}}$ materials.

Organizers:

H.-U. Habermeier, Max-Planck-Institut für Festkörperforschung, Heisenbergstrasse 1, D7000 Stuttgart 80, W. Germany; telephone (49) 7116860231 ; fax (49) 7116874371.

E. Kaldis, Laboratorium für Festkorperphysik, ETH - Honggersberg/HPF, CH8093 Zurich, Switzerland; telephone (41) 1 377 22 31; fax (41) 13715989.

\section{Symposium B-Metal Matrix Composites}

In recognition of recent material achievements and current industrial interest in this subject, the symposium will be the first Pan-European meeting directed solely to metal matrix composites. The symposium will cover all aspects of MMCs and will be divided into five separate sessions: - Manufacturing techniques: liquid state and solid state processing, preform technology;

- Interfacial phenomena: wetting; thermal stability; characterization;

- Mechanical properties: static and dy- namic testing, defect tolerance, $\mathrm{NDE}$ - Post production processing: forming, machining, joining, and

- Applications: components and service experience.

Organizers:

Geoff Chadwick, Hi-Tec Metals R\&D Ltd., Millbrook Close, Chandlers Ford, Southampton, SO5 3BZ, England; telephone (44) 703 255510; fax (44) 703267607.

Ludo Froyen, Departement Metaalkunde, Katholieke Universiteit Leuven, 3030 Heverlee, Belgium; telephone (32) 162209 31; fax (32) 16207995.

Tony Bunsell, Centre des Matériaux, Ecole Nationale Supérieure des Mines de Paris, 91003 Evry Cedex, France; telephone (33) 1 60763015 ; fax (33) 160884757.

\section{Symposium C-Magnetic Thin Films, Multilayers and Superlattices}

This symposium will bring together scientists interested in the experimental and theoretical advances in this area of materials science, from both a fundamental as well as applied research point of view. Contributed papers are solicited in, but not limited to, the following areas:

- Growth and characterization;

- Magnetic and magneto-optic properties; surface and interface anisotropies;

- Spectroscopic methods: (spinpolarized) electron, neutron, Mössbauer, optical and synchrotron radiation studies;

- Magnetic imaging and domain structure;

\section{If your library doesn't subscribe to Journal of Materials Research, don't you think it should?}

\author{
Your colleagues will benefit from JMR's \\ - new monthly publication schedule \\ - distinguished editorial leadership \\ Walter L. Brown, Editor in Chief \\ Shigeyuki S̄ōmiya, Assoc. Editor \\ (Japan); \\ Werner L. Lutze, Assoc. Editor \\ (Europe)
}

\author{
- interdisciplinary emphasis \\ - accessibility-JMR is referenced in Chem \\ Abstracts, Current Physics Index, Science \\ Citation Index, Metals Abstracts, INSPEC, \\ and many other key bibliographic systems.
}

...and You will benefit by always having a "backup" in case you loan out your copy of JMR.

Tell your librarian about Journal of Materials Research! 
- Theory: band structure and related properties, anisotropy, collective phenomena; and

- Applications of magnetic and magnetooptic thin films and superlattices.

Organizers:

A. Fert, Laboratoire de Physique des Solides, Université de Paris Sud, F-91405 Orsay, France; telephone (33) 169415324 ; fax (33) 169416086 .

G. Guntherodt, 2. Phys. Institut der RWTH Aachen, D-5100 Aachen, W. Germany; telephone (49) 241 807055; fax (49) 241803599.

\section{Symposium D-Metallurgical Coatings and Materials Surface Modifications}

This symposium aims to bring together participants from a wide cross section of activity in the coatings and surface modifications fields in order to foster an interchange of ideas and expertise. The symposium will be devoted to modern coatings processes, surface modification techniques, applications and characterization methods. Areas of interest include but are not limited to:

- Physical vapor deposition;

- Chemical vapor deposition;

- Plasma spraying and related techniques; - Surface treatments by laser, electrons and ion beams;

- Hard coatings including diamond like materials
- Tribological coatings;

- Surface treatment for corrosion resistance;

- New materials obtained by deposition techniques (metastable alloys); and

- Physical and mechanical properties determinations.

\section{Organizers:}

J. Spitz, Centre d'Etudes et de Recherches sur les Matëriaux, CENG, BP 85 X, 38041 Grenoble Cedex, France; telephone (33) 76 8839 09; fax (33) 76885152.

H. Hintermann, CSEM, P.O. Box 41, Rue Breguet 2, 2000 Neuchatel 7, Switzerland; telephone (41)38240161; fax (41)38252188.

B. Heinrich, Physics Department, Simon Fraser University, Burnaby, BC V5A1S6, Canada; telephone (1) 604 291-4402; fax (1) 604 291-3592.

E.E. Marinero, IBM Research Division, Almaden Research Center, 650 Harry Road, K32/803D, San Jose, California, 951206099, U.S.A.; telephone (1) 408 927-2016; $\operatorname{fax}(1) 408927-2100$.

\section{Symposium E-Surface Processing \& Laser-Assisted Chemistry}

This symposium will cover all aspects of energy beam materials processing, from basic studies to novel phenomena for applications and devices. It will focus on ion, electron, and photon beam assisted chemistry for localized and low temperature processing. Surface, interface and thin film reactions of dielectrics, semi- and superconductors, metals, organic and biological materials will be emphasized in terms of fundamental understanding and assessing the criteria for future practical applications. Specific topics will include:

- New organometallic precursors for surface processing;

- Kinetic studies of beam-stimulated reactions;

- Deposition, growth, doping and patterning of thin films;

- Ablation, etching, and cutting;

- Interface control and multilayers

- Process diagnostics and in-situ analysis;

- Novel approaches for integrated processing; and

- Industrial applications and device fabrication.

\section{Organizers:}

Ian W. Boyd, Electronic \& Electrical Engineering, University College London, Torrington Place, London WC1E 7JE, United Kingdom; telephone (44) 1380 7304; fax (44) 13874350 .

Eric Fogarassy, Laboratoire PHASE, C.R.N., 23, rue du loess, 67037 Strasbourg Cedex, France; telephone (33) 882862 57; fax (33) 88280990 .

Michael Stuke, Max-Planck-Institut für Biophys. Chemie, P.O. Box 2841, D-3400 Göttingen, W. Germany; telephone (49) 551201 338/563; fax (49) 551201530.

\section{PROMPT SRIIPMENT of MRS BOOKS to EUROPE, the MIDDLE EAST, and AFRICA by CLARKE ASSOCLTES-EUROPE LDLYED}

Clark Associates-Europe Limited now offers MRS book buyers in 30 European countries, 12 Middle East territories, and all of Africa:

$\square$ The ease of making payment in any major currency

$\square$ No prepayment or proforma requirement

$\square$ Faster shipment of MRS Symposium Proceedings, Conference Proceedings, and Extended Abstracts from UK stocks

$\square$ MRS members can buy at MRS member rates (plus a small handling charge)

European countries include: Austria, Belgium, Bulgaria, Cyprus, Czechoslovakia, Denmark, Finland, France, Germany (Federal and Democratic Republics), Greece, Hungary, Iceland, Ireland, Israel, Italy, Luxembourg, Malta, Netherlands, Norway, Poland, Romania, Spain, Sweden, Switzerland, Turkey, United Kingdom, USSR, Yugoslavia.

Middle East territories include: Bahrein, Egypt, Iran, Iraq, Jordan, Kuwait, Lebanon, Libya, Saudi Arabia, Syria, United Arab Emirates, Yemen.

Africa includes the entire continent. 